\title{
A participação da sociedade civil em instrumentos da política ambiental brasileira
}

\section{The Civil Society Participation in Instruments of the Brazilian Environmental Policy}

\author{
Roseli Nunes COLETTI*
}

\begin{abstract}
RESUMO
O artigo objetiva avaliar a participação da sociedade civil em processo decisório de alguns instrumentos da política ambiental brasileira, a saber: zoneamento ambiental, avaliação de impacto ambiental e o licenciamento ambiental, quando aplicados, destacando, ainda, a relevância da temática na atualidade. Para tanto, se faz uma breve revisão bibliográfica do tema em questão, com o intuito de estabelecer um arcabouço teórico conceitual acerca das possibilidades de participação pública nas tomadas de decisões ambientais. Utilizando o método de análise documental, evidencia-se a necessidade de se aprimorarem os instrumentos, as técnicas e os processos comunicativos, de forma a incentivar a ampla e irrestrita participação da sociedade civil em processos de tomada de decisão ambiental.
\end{abstract}

Palavras-chave: participação pública; processo decisório; zoneamento ambiental; avaliação de impacto ambiental, licenciamento ambiental.

\begin{abstract}
This paper focuses on the evaluation of the civil society participation in the decision-making process of a number of instruments of the Brazilian environmental policy, such as: environmental zoning, environmental impact evaluation, environmental licensing. The current relevance of the matter is emphasized. A brief literature review of the issue is done in order to establish a conceptual theoretical framework about the opportunities for public participation in environmental decision-making process. The need to improve the instruments, techniques and communicative processes is emphasized through documental analysis, in order to encourage a wide and unrestricted participation of the civil society in decision-making of the environmental processes.
\end{abstract}

Keywords: public participation; decision-making; environmental zoning; environmental impact assessment, environmental licensing. 


\section{Introdução}

A percepção de que a harmonia com o meio ambiente estava se rompendo, encontrando-se, portanto, o ponto de resiliência em vias de extrapolação, veio à tona a partir do lançamento da obra Primavera silenciosa, editada em 1962 por Rachel Carson. Focando a utilização de produtos químicos para o controle de pragas e doenças, Carson informou ao mundo a interferência destes nas defesas do ambiente natural. Tal livro provocou reações diversas, tanto favoráveis como também desfavoráveis em diversos campos do conhecimento humano.

Todavia, o marco conceitual da conscientização planetária em relação ao uso indiscriminado e indevido dos recursos ambientais se deu na Conferência Mundial das Nações Unidas sobre o Meio Ambiente Humano, ocorrida em Estocolmo, em 1972.

As constatações acerca da problemática ambiental, apresentadas naquela data, provocaram pressões generalizadas para que os países se reestruturassem, de forma a redefinirem suas políticas ambientais nacionais no controle e na exploração dos seus recursos naturais.

Vale lembrar que o priorizado em escala ascendente, até então, pela sociedade humana, tem sido a satisfação imediata das suas necessidades. Para tanto, o ser humano tem se utilizado da natureza em todas as suas formas, estendendo seu domínio, poder e autoridade presumida sobre as demais espécies do planeta, objetivando dominá-las.

Essa prática de buscar controlar as forças da natureza, criando o mito de poder, indefinida e impunemente, transformá-la de acordo com as suas necessidades momentâneas, por meio das inovações tecnológicas, culturais, econômicas e sociais, integra a linha de raciocínio da ciência econômica tradicional. Cabe ressaltar que a estruturação de tal modelo tem se mantido, até então, atada aos moldes lineares, tendo por prática, quando da sua aplicação, a negação da relação ou da interdependência entre as variáveis econômicas e não-econômicas.

Um dos resultados negativos dessa "visão de mundo" é o fato de influenciar as ações de diversos segmentos da sociedade (incluindo-se aí o governo, em todas as suas esferas, a indústria, e o comércio) provocando, assim, sérias e negativas repercussões para a população em geral, haja vista colocar a efetividade e a sustentabilidade do desenvolvimento muito aquém do esperado.

Muitos são os exemplos, podendo-se citar as mudanças climáticas, a poluição das águas, a séria situação dos resíduos sólidos e a chuva ácida. Todos evidenciam que, após longos anos de depredações, a natureza está dando sinais de esgotamento. Demonstram, igualmente, que os desequilíbrios ocasionados estão tornando o planeta inadequado inclusive para a habitação humana.

Os citados problemas, aliados às pressões mundiais, provocaram profundas transformações na gestão da coisa pública no Brasil. Dentre elas, as que mais se destacaram foram o aumento e a consolidação da cidadania, articuladas a novos processos políticos que objetivam dar suporte à ampliação do elenco de atores sociais envolvidos na elaboração das políticas de gestão pública.

Esta dinâmica de mobilização civil assinalou, por conseguinte, uma inflexão relevante no que tange ao padrão decisório estatal, visto impor uma ruptura com os modelos não democráticos de articulação entre Estado e sociedade, lembrando que aquele, até então, privilegiou relacionamentos fulcrados no clientelismo, no corporativismo e no insulamento burocrático.

Nesse cenário, pode-se afirmar que vem ocorrendo uma redefinição nos papéis assumidos tanto pela sociedade civil quanto pelo aparelho estatal no trato de questões socioambientais. Tais mudanças implicam a edificação de novos arranjos institucionais que visam à debelação de um modelo de Estado centralizador, característico das administrações públicas burocratizadas.

Diante de tal quadro, ainda não plenamente consolidado, a sociedade passaria a atuar participando da elaboração, da gestão e da implementação do conjunto de ações exercidas pelo ente governamental.

Trata-se, assim, de encontrar, por meio do trabalho conjunto do setor público com a sociedade civil, um ponto de equilíbrio entre objetivos que, se não analisados sistemicamente, tornam-se conflitantes, ou seja; buscar compatibilizar gradativamente e igualitariamente os avanços científicos/tecnológicos aliados à preservação ambiental.

\section{A participação da sociedade civil em processo decisório ambiental}

A temática da participação da sociedade em processo decisório estatal tem atraído a atenção de teóricos de todo o planeta ultimamente, principalmente em se tratando de políticas ambientais. Tal proceder se fundamenta na crença de se poder, ao utilizar essa forma de manifestação social, atingir níveis de desenvolvimento qualitativamente melhores. 
Esta modalidade de gestão emerge com o intuito de dar uma resposta efetiva à incessante busca por um regime democrático capaz de confrontar problemas e conflitos ambientais que são, dada sua natureza, extremamente complexos e, portanto, não fáceis de serem resolvidos por uma perspectiva unidisciplinar, mas sim por uma ótica multidisciplinar.

Nesse sentido cabe citar James e Blamey (1999), ao desenvolverem estudos sobre a participação pública em tomada de decisão na Austrália.

Segundo eles, há muitos métodos - cerca de trinta e abordagens que tratam da participação da sociedade em processo decisório ambiental. Porém, de nada adianta essa diversidade se a participação efetiva e prévia não ocorrer. Comprovam sua retórica relatando os problemas ocorridos em um caso, usado como exemplo, por falta de participação social. Atestam, ainda, que os fracassos em programas de desenvolvimento são decorrentes das inadequações dos projetos e da implementação, por falta de envolvimento das populações locais.

Também, vale recordar, os resultados apresentados na Conferência sobre Participação Pública em Processos de Tomada de Decisão Ambiental, realizada na Rússia, em 1997 (ZHAVORONKOVA et al., 1997). Naquela ocasião, chegou-se à conclusão que algumas providências deveriam ser tomadas para que todos os cidadãos viessem a ter seu direito de voz garantido, principalmente quando o tema é a proteção do meio ambiente, pois este diz respeito a todos os segmentos da sociedade.

Tal preocupação adveio do resultado de estudos que, segundo os pesquisadores, comprovou o desrespeito de oficiais russos para com os direitos ambientais, quando da execução de projetos relacionados a usinas nucleares, violando, igualmente, a Constituição da Federação Russa. Atestam eles que isso gerou impactos ambientais diversos e colocou a vida e a saúde da população em perigo. Além disso, tais violações provocaram o descrédito da sociedade na justiça, o que é, segundo os autores, particularmente alarmante para o crescimento da conscientização do público e para criar um mecanismo viável de proteção legal. Desse modo, naquela Conferência, os pesquisadores envolvidos chegaram à conclusão que aquele país se encontrava ainda em estágio de desenvolvimento inicial no concernente à participação da sociedade em tomada de decisão ambiental.

Há que se falar ainda dos exemplos apresentados por Doelle e Sinclair (2006), em estudos realizados no Canadá. Este país, apesar de já contar com mais de três décadas de experiência em participação da sociedade em tomada de decisão ambiental, ainda não pode ser considerado como um exemplo de efetividade no concernente à participação da sociedade civil em questões estatais. Isto porque os processos de participação pública são definidos como ineficazes e caros pelos participantes; como demorados pelos proponentes; e como ineficientes pelos governos (PETTS, 1999 apud DOELLE; SINCLAIR, 2006).

Para eles, o problema se encontra no foco que é dado à participação, ou seja este é centrado no acesso e no processo (eficiência), ao invés de nos resultados (eficácia).

Qualquer que seja o motivo, segundo os autores, o efeito de tal prática é que o administrador provinciano encoraja essencialmente o proponente a completar a avaliação ambiental antes que haja a participação da sociedade, ou seja, esta última não estaria sendo prévia e dirigida aos resultados, mas sim aplicada no meio do processo e direcionada a esse, o que não a torna efetiva.

Em face disso, acreditam eles que o problema fundamental é a falta de reconhecimento da necessidade de participação prévia e contínua e, igualmente, uma ausência de abertura para repensar um projeto na ocasião em que o público seja efetivamente envolvido.

Assim, se o público for envolvido na fase inicial da tomada de decisão - participação prévia, considerada a mais efetiva (ZHAVORONKOVA et al., 1997; JAMES; BLAMEY, 1999; UNECE, 2004; DOELLE; SINCLAIR, 2006; VALLE, 2005; dentre diversos) - pode-se prevenir ou mitigar conflitos e consequências ambientais adversas. Ademais, como resultado da participação pública, até e incluindo a decisão final, tem-se um processo mais transparente e legítimo (VALLE, 2005; ZHOURI; LASCHEFSKI; PEREIRA, 2005).

Em tempo, vale lembrar que na reunião de Cúpula das Américas, realizada na cidade de Miami em 1994, foi salientada a relevância da participação da sociedade civil na área ambiental. Igualmente, em 1996, na Conferência de Cúpula sobre Desenvolvimento Sustentável, ocorrida em Santa Cruz de La Sierra, os países das Américas reconheceram que o alcance de um desenvolvimento que se diga sustentável requer o compromisso e a participação de todos. Ainda na Cúpula das Américas, realizada em Santiago em 1998, os governos comprometeram-se com a promoção da participação da sociedade civil na esfera pública.

Em termos de participação, cabe ainda explicitar que ela se subdivide em diversas formas ou tipos, bem como graus ou níveis, assim classificados de acordo com Arnstein 
(1969). Não se pretende aqui descrever exaustivamente todos eles, mas apenas relatar como ela é descrita por um renomado pesquisador, demonstrando, igualmente, o nível considerado como o ideal na escala da participação.

Sendo assim, para este autor, os tipos de participação podem ser representados por uma escada ascendente como descrito na sequência: nos dois primeiros degraus - manipulação e terapia -, é entendido que não existe participação, visto que é o setor público quem conduz todo o processo. Desse modo, a real pretensão desses degraus é não deixar que as pessoas participem do planejamento e/ou tomadas de decisões. Objetiva, assim, esses níveis, permitir que os detentores do poder "eduquem" ou "curem" os participantes. Dessa forma, as pessoas são colocadas em comitês de consultoria com o expresso desejo de obter seu apoio. Mascara-se por conseguinte a participação.

Nos três degraus seguintes - informação, consulta e aplacação - que são chamados de graus intermediários, os atores sociais não participam da tomada de decisão, mas podem ouvir e são ouvidos. Nesse nível não há nenhuma garantia de que o status quo será mudado. É, portanto, um nível onde ocorre uma participação demagógica. É de bom alvitre salientar que o grau cinco - aplacação - funciona como uma falsa justiça, isto porque as regras permitem que os "sem-poder" aconselhem, mas são os detentores do poder que continuam a decidir.

Nos três últimos degraus - aliança, poder delegado e controle cidadão - considerados como o máximo em participação, se pretende que o cidadão governe junto com o governante. Vale especificar que o grau seis permite apenas negociação e acordos. Já nos degraus sete e oito os cidadãos possuem a maioria dos assentos nas tomadas de decisão, mantendo assim um poder administrativo completo (ARNSTEIN, 1969). De acordo com Vega e López (2001), esse é um objetivo utópico, mas considerado o ideal para se obter a sustentabilidade ambiental.

Diante do explanado e em consonância com o pensamento dos autores pesquisados, pode-se afirmar que o grau ideal para que a participação ocorra efetivamente é o que se situa no âmbito da autogestão, por ser ele o que mais poder atribui à sociedade.

Nele os grupos determinam seus objetivos, seus meios de trabalho e os controles que utilizarão sem haver a necessidade de se reportar à autoridade externa. Nesse nível não há diferença entre administradores e administrados, como explicitado por Bordenave (1994). O autor atesta, igualmente, que em uma sociedade verdadeiramente participativa o controle final das decisões, nos níveis mais elevados, cabe ao povo.

\section{A indispensável presença da sociedade civil na aplicação de instrumentos da política ambiental nacional}

É com o movimento ambientalista, emergido a partir da reflexão de biólogos e economistas norte-americanos, em fins da década de sessenta do século passado, que a sociedade civil se interessa e começa a se envolver com as questões ambientais/estatais. Consequentemente, passa a buscar informações e a se instrumentalizar para que os direitos de primeira, de segunda, de terceira, de quarta e de quinta gerações, em âmbito mundial, sejam priorizados quando da regulamentação de atividades contaminantes do meio ambiente.

É importante registrar que o Banco Mundial, em meados da década de setenta, fez fortes pressões para que o governo brasileiro se posicionasse, formalmente, no intuito de conscientizar a população acerca da problemática ambiental interposta.

Deste modo, tal instituição exerceu uma influência decisiva na formulação da política ambiental brasileira, provocando, igualmente, o desenvolvimento de estudos e pesquisas tecnológicas que visavam abrandar os problemas ambientais e ampliar o nível de conhecimento dos profissionais atuantes na área. A solidificação dessa manifestação se deu com a inserção do Capítulo VI, dedicado ao Meio Ambiente, na Magna Carta de 1988. Esses acontecimentos culminaram na realização da Conferência das Nações Unidas sobre o Meio Ambiente e Desenvolvimento - Eco-92 -, sendo esta a expressão máxima da preocupação nacional em torno dos assuntos relacionados ao ambientalismo nacional (FLORIANO, 2004).

A insurgência da Política Nacional do Meio Ambiente brasileira foi, destarte, um reflexo da realidade ambiental e social do país à época. Sendo assim, atendendo ao normatizado na Lei 6.938/81 em seu artigo $4^{\circ}$, I, ela visa compatibilizar o desenvolvimento econômico e social com a preservação da qualidade do meio ambiente e do equilíbrio ecológico. Para lograr tal objetivo, busca incorporar diversas dimensões da vida em sociedade, como preceituado pelo desenvolvimento sustentável, a saber: a social, a econômica, a espacial, a política, a ambiental, a cultural etc. (LANNA, 2007). 
Nesse intento, foram instituídos diversos mecanismos, elencados no artigo $9^{\circ}$ da Lei 6.938/81 (BRASIL, 1981); São eles os instrumentos da Política Nacional do Meio Ambiente, dentre outros, pode-se lá encontrar: o zoneamento ambiental - ZA, a avaliação de impacto ambiental - AIA - e o licenciamento ambiental - LA.

Este artigo foca-se nas três categorias de instrumentos da Política Ambiental brasileira, citados acima, com o fito de destacar como se dá a participação da sociedade civil nos mesmos.

\subsection{Zoneamento Ambiental}

O vocábulo zoneamento está relacionado, desde seu surgimento tanto na Europa quanto nos Estados Unidos, ao planejamento urbano. Portanto, em países de pouca extensão territorial e ocupação densa, tais como o Japão e a Holanda, ele acabou se tornando uma ferramenta indispensável. No Brasil, dada a sua ampla extensão territorial e - em sua maior parte - baixa densidade demográfica, tem sido pouco utilizado fora da área urbana das grandes cidades (RIBEIRO, 1998, apud BATISTELA, 2007).

Segundo Batistela (2007), ao se conciliar o termo zoneamento com a palavra ambiental, procurou-se agregar ao primeiro conceitos de disciplinas diversas e, em especial, os da ecologia, que é o campo do planejamento territorial. Tem, por conseguinte, o escopo de definir os usos possíveis de zonas territoriais (urbanas, rurais e as protegidas) sob os pontos de vista artístico, cultural e paisagístico, dentre diversos outros. Sendo assim, pode ser visto como um meio norteador de políticas, planos e programas governamentais.

Para tanto, é realizado por meio de critérios científicos, bem como por aqueles expressos pela sociedade civil, considerando o maior número possível de fatores ambientais que sejam relevantes para os tipos de ocupação estudados, a saber: industrial, agrícola, urbano etc. (SOUZA et al., 2005).

Segundo Oliveira (2004), o ZA possui uma especificidade muito mais indicativa do que normativa, isto é, ele preocupa-se, por meio da participação da sociedade civil e de critérios técnicos, em indicar possibilidades de ocupação. Torna-se, portanto, um precioso instrumento de apoio ao processo decisório das políticas, planos e programas ambientais.

Sua conceituação jurídica encontra-se expressa no artigo $2^{\circ}$ do Decreto 4.297, de 10 de julho de 2002 (BRASIL, 2002), transcrito como zoneamento ecológico econômico
- ZEE - instituto responsável pela regulamentação de tal mecanismo normativo. Nesse se lê, textualmente, que o zoneamento é um "[...] instrumento de organização do território a ser obrigatoriamente seguido na implantação de planos, obras e atividades públicas e privadas [...]". Utiliza-se para tanto de meios padronizados no concernente à proteção ambiental com o intuito de garantir a qualidade ambiental "[...] dos recursos hídricos e do solo e a conservação da biodiversidade, garantindo o desenvolvimento sustentável e a melhoria das condições de vida da população" (BRASIL, 2002). Resta evidente que é atribuída ao ZA a concretização de sua função de acordo com a legislação que o criou (Política Nacional do Meio Ambiente e respectivo Decreto), atendendo aos princípios de sustentabilidade (SOUZA et al., 2005).

A definição dos critérios básicos a serem utilizados na realização de um ZAé de responsabilidade do Poder Público, valendo-se, para tanto, da edição de leis e regulamentos. No entanto, para atingir seus objetivos, lhe é indispensável a participação do cidadão. Isto em virtude da ordenação territorial, dentre outros, conferir à sociedade especiais interesses, principalmente em seu local de moradia.

O objetivo do ZA é o de servir de base aos demais instrumentos de planejamento de licenciamento, tais como: o LA; o EIA (Estudo de Impacto Ambiental); o Plano de Bacia etc. De acordo com Souza et al. (2005, p. 8), tal característica, dentre outras, o situa entre os mecanismos que visam dar "[...] respostas essencialmente ambientais, portanto dinâmicas, e que não se propõe ser estanque quando se relaciona com o uso do solo."

No pensar de Machado (2001), o ZA deve, necessariamente, passar por um amplo e aberto debate, de forma que todos os setores da sociedade participem expressando suas opiniões. Acredita o autor que desse modo o desenvolvimento local ocorrerá sem agressões aos recursos naturais.

Sendo assim, na ausência de tal forma de participação, quando da sua elaboração ou ainda, no caso de existir a possibilidade de manipulação dos dados por parte de alguns atores, tanto do setor público quanto do privado, a sua efetividade poderá estar comprometida.

Cabe, enfim, ressaltar que a maior parte das cidades brasileiras não possui o ZA. Isto torna mais difícil uma participação efetiva da sociedade civil, mesmo que organizada, nos outros instrumentos da Política Nacional do Meio Ambiente (PNMA), uma vez que, como já visto, caberia ao ZA possibilitar uma visualização espacial prévia e acurada das potencialidades territoriais frente a uma demanda a ser 
avaliada. Tal asseveração pauta-se no fato de a participação, nesses casos, acontecer apenas no meio ou no fim do processo e, mesmo assim, a tendência é a de que ela, pela ausência de um estudo prévio - ZA - das zonas consideradas as melhores para determinados empreendimentos, venha majorar o tempo e os custos do processo, levando o empreendedor e o decisor a buscar formas de esquivar-se dela.

\subsection{Avaliação de Impacto Ambiental}

No Brasil, a primeira experiência de AIA ocorreu no ano de 1972, quando da construção da usina hidrelétrica de Sobradinho. A partir de então muitas outras foram realizadas. Porém, é importante relatar que as conclusões obtidas em tais estudos muito raramente foram utilizadas para prevenir ou mesmo evitar impactos, não servindo, portanto, para o fim a qual se destinavam. No começo, tais AIAs foram executadas por estrangeiros habilitados nessa área, mas aos poucos especialistas brasileiros, além de instituições de pesquisa e consultoria, adentraram no processo, sendo que os últimos estudos realizados, entre 1972 e 1986, já o foram por especialistas nacionais (MOREIRA, 1995).

Sua regulamentação aconteceu, primeiramente, em âmbito estadual, no ano de 1977, tendo sido instituída pelo ato que regia o Sistema de Licenciamento de Atividades Poluidoras - SLAP - do Rio de Janeiro. Foi, contudo, com a criação da Lei da Política Nacional do Meio Ambiente (6.938/81) que a AIA se efetivou em território nacional; sendo essa incorporação ratificada por meio do artigo 225 da Constituição Federal Brasileira de 1988 - CF/88, ao tornar obrigatória a realização de EIA/RIMA inclusive para atividades potencialmente poluidoras (SÁNCHEZ, 2006). A partir de então, a AIA se tornou um instrumento essencial da Política Nacional do Meio Ambiente para a gestão - em nível federal, estadual ou municipal - institucional de políticas, planos e programas (BRASIL, 1995).

A AIA, no Brasil, encontra-se vinculada ao licenciamento ambiental, sendo conduzida prioritariamente pelos órgãos estaduais do meio ambiente. Ela é um processo, dentro do qual se realiza o Estudo de Impacto Ambiental -o qual, por seu turno, se constitui em seu elemento-chave com seu respectivo relatório -, lembrando que este último deve ser escrito em uma linguagem não técnica de forma que a população em geral, ao acessá-lo, possa compreender seu conteúdo (SÁNCHEZ, 2006).
Como ferramenta da Política Nacional do Meio Ambiente, ela possui algumas dimensões no que diz respeito ao processo decisório. São elas: a dimensão política - relaciona-se, esta, com o grau de proteção ambiental que os representantes do poder público têm por obrigação garantir, dada a natureza de seu cargo, harmonizando-as com as outras políticas do Estado ou do país; a dimensão de conteúdo - correspondente ao estudo de impacto ambiental com seu respectivo relatório - EIA/RIMA, normatizados pela Resolução do Conselho Nacional do Meio Ambiente - CONAMA 001/86 (BRASIL, 1986), artigos $5^{\circ}$ e $6^{\circ}$; e a dimensão processual - referente à institucionalização jurídica da AIA, a qual se incorporará ao processo quando da decisão final (QUEIROZ, 1995).

O EIA é, assim, um dos mecanismos fundamentais para a concretização de processos de licenciamento ambiental de atividades que sejam efetivas ou potencialmente poluidoras. Sendo assim, por ser um instrumento técnico que, no Brasil, subsidia o licenciamento ambiental, tem por dever a discriminação de todos os aspectos técnicos inerentes ao projeto em exame. Eis o porquê de a análise de risco - AR - se alicerçar nele (SOUZA, 2000; QUEIROZ, 1995).

Queiroz (1995) afirma, ainda, que o RIMA, como um resultante do EIA, é outro componente essencial no processo da AIA. Ele também possui amparo legal e formal, tendo por escopo esclarecer a população acerca do projeto, obra ou atividade a ser implementada.

Um último componente da AIA, referido pela escritora citada, é o da Audiência Pública - APub - que se traduz, como já visto, em um possível acesso da população na fase de comentários.

\subsection{Licenciamento Ambiental}

A primeira experiência brasileira com esse instrumento se deu no Rio de Janeiro no ano de 1977, quando se criou o Sistema de Licenciamento de Atividades Poluidoras. Tal iniciativa não tinha força de lei. Desse modo, sua aplicação restringia-se às atividades poluidoras de empreendimentos industriais (MOREIRA, 1995).

Essa modalidade da política ambiental só passou a adquirir caráter impositivo no Brasil a partir da Lei Federal de Zoneamento Industrial de Áreas Críticas de Poluição - Lei ${ }^{\circ}$ 6.803/80 (BRASIL, 1980). No entanto, ela só estendeu seu controle para além de atividades poluidoras a partir do Decreto ${ }^{\circ} 88.351$ de 1983 que regularizou a Lei 
6.938-81 (BRASIL, 1981). Tal norma determina que toda atividade potencialmente degradadora do meio ambiente deve se submeter ao processo de licenciamento ambiental. A regulamentação final de tal instrumento se deu por meio da Resolução $n^{\circ}$ 01/86 do CONAMA (BRASIL, 1986), ao atribuir as devidas responsabilidades aos Estados (MOREIRA, 1995).

Um dos objetivos principais do LA é o de conciliar interesses conflituosos, tais como questões de emprego, o nível da atividade econômica e a produção de riquezas, dentre outros, com a garantia de sobrevivência das gerações futuras (FINK et al., 2004).

Assim sendo, cabe ao processo de licenciamento ambiental estabelecer as condições, restrições e medidas de controle ambiental a serem cumpridas pelo empreendedor - pessoa física ou jurídica -, que tanto pode ser o setor público quanto o privado, para instalar, operar, ou ampliar atividades potencialmente poluidoras ou utilizadoras de recursos naturais, ou ainda, aquelas que, sob qualquer forma, possam causar degradação ambiental. Tal proceder vincula-se às disposições legais e regulamentares, bem como às normas técnicas aplicáveis ao caso.

A licença a ser obtida é una e genérica, compreendendo várias fases da atividade. No Brasil há três etapas a serem seguidas nos processos de licenciamento, sendo que cada uma delas corresponde a uma licença específica. São elas: licença prévia - LP - permissão para instalar, seria a fase preliminar do projeto; licença de instalação - LI - início da implantação, verificando-se se está de acordo com a licença anterior, e licença de operação - LO - ela autoriza o funcionamento da atividade, desde que esteja de acordo com as licenças anteriores (FINK et al., 2004).

Dentre os estudos ambientais que compõem a fase preliminar do pedido de licença, destaca-se o EIA-RIMA, que é um instrumento previsto na Constituição Federal de 1988, sendo considerado personagem principal do modelo de prevenção de danos ao meio ambiente. Tal ferramenta deve ser prévia à implantação do empreendimento e ao início da atividade e instruirá o pedido de licença das atividades que causem significativa degradação ambiental (FINK et al., 2004).

Desta maneira, é atribuído ao licenciamento ambiental - como instrumento preventivo de gestão da política ambiental - o ofício de garantir a edificação de um desen- volvimento que coexista harmoniosamente com o meio ambiente. Para tanto, deverá estar alicerçado na participação da sociedade, buscando, conjuntamente, a eficiência econômica, a equidade social e a qualidade ambiental. O licenciamento, assim entendido, detém a capacidade de atuar como o fomentador de uma interação sincronizada entre o empreendedor, o Estado e a sociedade, garantindo que os objetivos dispostos nas políticas estabelecidas sejam cumpridos. Tal proceder pode contribuir para uma melhor qualidade de vida das gerações que estão por vir (SÃO PAULO, 2007).

\section{Análise da participação da sociedade em alguns instrumentos da política ambiental nacional}

Sumarizam-se no quadro abaixo, para efeito de análise, algumas informações acerca dos instrumentos abordados.

Como visto no quadro ilustrativo, a participação da sociedade civil em processo decisório dos instrumentos da PNMA abordados se dá por meio de Consultas Públicas, Audiências Públicas ou Colegiados. Percebe-se, igualmente, que a possibilidade de participação prévia, considerada a mais efetiva, só se dá no ZA. Contudo, como este tem sido muito raramente utilizado, pode-se afirmar que no Brasil a participação nos instrumentos da Política Ambiental Nacional aqui abarcados só acontece no meio ou em fins do processo.

Outro ponto relevante a ser ressaltado, de acordo com Queiroz (1995), é que as audiências públicas - a forma mais utilizada para a participação da sociedade no país, neste setor estão sendo subutilizadas em razão de, em alguns Estados brasileiros, elas não serem uma exigência para todos os EIA/RIMA apresentados. Deste modo, segundo a autora, a sociedade tem sido deixada, quando possível, de lado nas tomadas de decisões concernentes à área ambiental.

Vale, ainda, lembrar que as audiências públicas possuem um caráter muito mais formal e legal do que prático, em detrimento, portanto, da sua efetividade. ${ }^{1}$ Deste modo, tal instrumento está sendo utilizado pelo decisor em razão dos dispositivos legais que assim o determinam, mas não por sua real vontade.

\footnotetext{
${ }^{1}$ Ver mais sobre o tema em Alonso e Costa (2004).
} 
QUADRO 1 - A PARTICIPAÇÃO DA SOCIEDADE CIVIL EM INSTRUMENTOS DA PNMA

\begin{tabular}{|c|c|c|c|}
\hline MODALIDADES & ZONEAMENTO AMBIENTAL & $\begin{array}{l}\text { ESTUDO IMPACTO AMBIENTAL/ } \\
\text { RELATÓRIO IMPACTO AMBIENTAL }\end{array}$ & $\begin{array}{l}\text { LICENCIAMENTO } \\
\text { AMBIENTAL }\end{array}$ \\
\hline TIPO DE PARTICIPAÇÃO & $\begin{array}{l}\text { AUDIÊNCIA PÚBLICA } \\
\text { CONSULTA PÚBLICA }\end{array}$ & $\begin{array}{l}\text { AUDIÊNCIA PÚBLICA } \\
\text { CONSULTA PÚBLICA }\end{array}$ & $\begin{array}{c}\text { AUDIÊNCIA PÚBLICA } \\
\text { CONSULTA PÚBLICA COLE- } \\
\text { GIADO } \\
\end{array}$ \\
\hline $\begin{array}{c}\text { FORMA DE } \\
\text { PARTICIPAÇÃOO }\end{array}$ & $\begin{array}{l}\text { PROCESSO POLÍTICO/ } \\
\text { ADMINISTRATIVO }\end{array}$ & $\begin{array}{l}\text { PROCESSO POLÍTICO/ } \\
\text { ADMINISTRATIVO }\end{array}$ & $\begin{array}{l}\text { PROCESSO POLÍTICO/ } \\
\text { ADMINISTRATIVO }\end{array}$ \\
\hline $\begin{array}{l}\text { MOMENTO DA PARTICI- } \\
\text { PAÇÃO CIVIL }\end{array}$ & PRÉVIA & MEIO & $\begin{array}{c}\text { MEIO } \\
\text { FIM }\end{array}$ \\
\hline $\begin{array}{c}\text { PODER DECISÓRIO } \\
\text { QUE OUTORGA }\end{array}$ & CONSULTIVO & CONSULTIVO & $\left\{\begin{array}{c}\text { CONSULTIVO } \\
\text { CONSULTIVO OU } \\
\text { DELIBERATIVO } \\
\text { MISTO }\end{array}\right.$ \\
\hline CARÁTER & PREVENTIVO & PREVENTIVO & PREVENTIVO \\
\hline CRITÉRIO DE ANÁLISE & TÉCNICA/SOCIAL & TÉCNICA/SOCIAL & TÉCNICA/SOCIAL \\
\hline BASE LEGAL & $\begin{array}{c}\text { DECRETO } \mathrm{N}^{\circ} 4.297 / 2002 \text { Art. } 2^{\circ} \\
\text { CF } / 88 \text { Art. } \mathrm{N}^{\circ} 225, \text { III }\end{array}$ & $\begin{array}{c}\text { LEI No } 6.938 / 81 \\
\text { LEI } 10.165 / 00 \\
\text { RES. CONAMA N }{ }^{\circ} 01 / 86 \\
\text { CF/88 Art. No } 225, \text { IV }\end{array}$ & $\begin{array}{c}\text { LEI N }^{\circ} 6.803 / 80 \\
\text { LEI N }^{\circ} 6.938 / 81 \\
\text { LEI } 10.165 / 00 \\
\text { DECRETO No } 88.351 / 83 \\
\text { DECRETO N }{ }^{\circ} 99.274 / 90 \\
\text { RESOLUÇÃO CONAMA No } \\
\text { 01/86 (ver alterações: } 11 / 86 ; 05 / 87, \\
\text { e 237/97) }\end{array}$ \\
\hline $\begin{array}{l}\text { PREVISÃO DO NÍVEL DE } \\
\text { PARTICIPAÇÃO } \\
\text { (ARNSTEIN, 1969) }\end{array}$ & $\begin{array}{c}7 \\
\text { PODER DELEGADO }\end{array}$ & $\begin{array}{c}3 \\
\text { PASSIVO }\end{array}$ & $\begin{array}{c}3 \\
\text { PASSIVO } \\
6 \\
\text { ALIANÇA }\end{array}$ \\
\hline FINALIDADE & $\begin{array}{l}\text { APOIO AO PROCESSO DECISÓRIO } \\
\text { VISANDO CONCILIAR INTERES- } \\
\text { SES CONFLITUOSOS }\end{array}$ & $\begin{array}{l}\text { APOIO AO PROCESSO DECISÓRIO } \\
\text { VISANDO CONCILIAR INTERESSES } \\
\text { CONFLITUOSOS }\end{array}$ & $\begin{array}{c}\text { APOIO AO PROCESSO } \\
\text { DECISORIO } \\
\text { VISANDO CONCILIAR INTE- } \\
\text { RESSES CONFLITUOSOS }\end{array}$ \\
\hline ÂMBITO ATUAÇÃO & $\begin{array}{l}\text { FEDERAL } \\
\text { ESTADUAL } \\
\text { MUNICIPAL }\end{array}$ & $\begin{array}{l}\text { FEDERAL } \\
\text { ESTADUAL } \\
\text { MUNICIPAL }\end{array}$ & $\begin{array}{l}\text { FEDERAL } \\
\text { ESTADUAL } \\
\text { MUNICIPAL }\end{array}$ \\
\hline EFICÁCIA & INDICATIVA & PRESCRITIVA & PRESCRITIVA \\
\hline APLICAÇÃO & $\begin{array}{l}\text { PRÉ-PLANEJAMENTO } \\
\text { PLANEJAMENTO }\end{array}$ & GESTÃO & CONTROLE \\
\hline
\end{tabular}

FONTE: Elaborado pela autora 
Publicação do IBAMA (BRASIL, 1995), ocorrida oito anos após a efetivação da AIA no Brasil, confirma o atestado acima, ao afirmar que o EIA/RIMA, a despeito de estar auxiliando os órgãos ambientais e também servir de instrumento de negociação entre a sociedade civil e os agentes envolvidos nos projetos propostos, contribuiu pouquíssimo para o aperfeiçoamento da gestão ambiental no seu todo.

Cabe esclarecer que "[...] não há na Constituição Federal nenhum dispositivo geral que estabeleça o direito de participação da sociedade em decisões políticas de interesse público, e tampouco há uma lei específica sobre direitos fundamentais que o estabeleça." (VALLE, 2005, p. 3).

Não se pode, contudo, olvidar que o artigo 225 da CF/88 (BRASIL, 1988) determina uma parceria entre o Poder Público e a sociedade quando da defesa do meio ambiente, o que, segundo o citado pesquisador, está sendo interpretado pela doutrina como princípio da cooperação, o qual, por sua vez, levaria à obrigatoriedade da participação social nos processos decisórios. O autor salienta, entretanto, que essa é apenas uma interpretação doutrinária, que não foi, ainda, validada por decisões judiciais, sendo, por conseguinte, muito mais principiológica do que prática (VALLE, 2005).

Deste modo, de acordo com o referido escritor, existe uma lacuna que deveria ser suprida "[...] na medida em que a ausência dessa previsão expressa limita a possibilidade de criar espaços participativos nos processos de tomada de decisão, notadamente naqueles referentes a assuntos macro." (grifou-se) (VALLE, 2005, p. 3).

Apesar disso, sabe-se que no quesito informação, a legislação nacional é uma das mais avançadas do mundo, além de ser considerada inédita e representar um avanço na seara do Direito Ambiental, segundo Furriela (2006), por incorporar tal princípio internacional - direito à informação -, acerca da democracia ambiental, no ordenamento jurídico de um país. Pois é inadmissível se falar em gestão ambiental participativa sem o acesso a uma informação fidedigna e pertinente e a tempo para que o processo decisório seja efetivo e a democracia para a defesa do meio ambiente se consolide (FURRIELA, 2006; VALLE, 2005).

Dessa forma, a Lei Federal de Informação Ambiental trouxe inovações no campo do acesso ativo à informação.
No entanto, segundo Valle (2005), elas só existem no papel, ou seja, não estão sendo divulgadas as listagens em consonância ao disposto no artigo $4^{\circ}$, muito menos tem sido cumprido o estabelecido no artigo $8^{\circ}$ da referida lei.

Barros (2004, p. 12) afirma que de nada adianta “[...] garantir o acesso a informações ambientais mediante a edição de normas, apenas para dizer que possuímos a melhor legislação nesse aspecto." O que se faz essencial, assim, é que elas sejam efetivamente aplicadas, estando, por conseguinte, o poder público preparado para tanto.

Diante do exposto, entende-se que o acesso à informação ambiental ativa e passiva no Brasil não é nem prévio, nem efetivo.

Quanto à participação, de acordo com os resultados da pesquisa realizada pela Associação Brasileira para o Desenvolvimento e Lideranças - $\mathrm{ABDL}^{2}$ - e pelo Instituto Socioambiental - ISA -, denominada "A iniciativa de acesso no Brasil", pode-se afirmar que também não é satisfatória. Isto porque tanto o marco legal como a prática encontram-se, ainda, em estágio intermediário de qualidade e acessibilidade.

O marco legal se refere à legislação; a qualidade está ligada aos esforços, por parte do Estado, para incorporar a participação da sociedade civil em seus processos de tomada de decisão, e a acessibilidade vincula-se às possibilidades de os afetados ou interessados obterem informações sobre como podem participar; a respeito do estado de um processo de tomada de decisão ou sobre o resultado de uma decisão.

A pesquisa aponta como ponto positivo o fato de existir, na atualidade, um processo democrático no país que impede "[...] a proibição da participação e do associativismo ou a existência formal de espaços onde esta possa ocorrer minimamente." (ABDL, 2005, p. 8).

No entanto, tal fato não quer dizer que a participação esteja ocorrendo satisfatoriamente, pois,

[...] nem mesmo o mais elementar, que é a disponibilização de informação relevante e oportuna aos interessados, [...] tem sido adequada, sendo frequentemente manipulada pelos responsáveis pelo avanço da política ou do projeto, especialmente nos processos de licenciamento de obras e implementação de políticas ambientais de grande escala. (ABDL, 2005, p. 8).

\footnotetext{
${ }^{2}$ A ABDL é uma organização brasileira que participa do projeto internacional para o aumento da iniciativa de acesso à informação, participação e justiça. Este é coordenado por uma rede global composta pelo WRI - World Resources Institute (Estados Unidos), o Environmental Management and Law Association (Hungria), Corporación Participa (Chile), Advocates Coalition for Development and Environmental (Uganda) e o Thailand Environment Institute (Tailândia).
} 
Também se tornou evidente, pela leitura do documento, que inexiste participação prévia, isto porque ela tem ocorrido apenas em etapas avançadas do processo de decisão, "[...] não havendo esforços genuínos do governo ou de setores investidores para envolver a população nos estágios iniciais estratégicos de tomada de decisão [...]." (ABDL, 2005, p. 8).

Outrossim, Alonso e Costa (2004) apontam ineficácia na realização de processos participativos nacionais. No estudo realizado por tais autores foi analisado o caso do Rodoanel em São Paulo. De acordo com tais pesquisadores as APubs " [...] foram realizadas em lugares que ficavam muito distantes de onde morava a população diretamente atingida pelas obras. [...]" (ALONSO; COSTA, 2004, p. 11). Além disso, elas não privilegiaram quatro municípios, que ficaram assim sem nenhuma audiência pública.

Asseveram, igualmente, que as convocações para as audiências não seguiram o preceituado na lei, qual seja, publicação em jornais populares, sendo encontradas apenas no Diário Oficial do Estado de São Paulo. Outro problema foi o horário de realização - das 19:00 às 24:00h - o que também tornou difícil a participação dos grupos sociais atingidos. Estas, além de outras elencadas pelos autores, são algumas das razões pelas quais a participação não foi efetiva, pois não preencheram suas exigências de publicidade e acessibilidade, no caso estudado.

Outro estudo a ser citado é o do órgão estadual responsável pelo processo de licenciamento de Minas Gerais, que é o Conselho de Política Ambiental - COPAM. Zhouri et al. (2005) ao realizarem uma análise dos trabalhos desenvolvidos por tal órgão concluíram que o mesmo, apesar de aparentar ser um espaço democrático e participativo, possui uma estrutura hierarquizada e oligárquica, "[...] pela qual se dá a perpetuação de uma visão dominante acerca dos recursos naturais. Esse livre e vicioso trânsito revela [...] um processo estrutural perverso." (ZHOURI et al., 2005 p. 96).

Prosseguem os autores asseverando que uma prática recorrente no COPAM é a aprovação de projetos com recomendação de indeferimento, dado por órgão técnico especializado, devido à inviabilidade socioambiental ou então pelo não cumprimento, por parte do empreendedor, de condicionantes indispensáveis à liberação do licenciamento. Citam inúmeros casos em que as licenças foram assim concedidas sem nenhuma justificativa para tal posicionamento.

Percebe-se, por conseguinte, que a participação pode ser maculada por uma minoria que utilizando a estratégia do discurso democrático como um avanço, ao levantar a bandeira da representatividade e da paridade na verdade o faz para elidir "[...] as tensões que perfazem os processos políticos em curso na nossa sociedade." (ZHOURI et al., 2005, p. 97).

Assim sendo,

[...] leis e normas são frequentemente reinterpretadas ou "adequadas" de forma a não impossibilitar projetos econômicos particulares que, via de regra, são anunciados como de interesse público. Ou seja, a legislação tem sido reinterpretada casuisticamente, em especial quando entendida como obstáculo ou quando se apresenta contrária ao modelo desenvolvimentista e aos interesses vorazes do mercado. (ZHOURI et al., 2005, p. 99).

Observa-se pelas experiências participativas usadas como exemplo que a realização de audiências públicas ou qualquer outro mecanismo tem o objetivo de referendar decisões previamente estabelecidas, bem como de configurar-se como instrumento de cumprimento de normas legais, e não de ouvir, realmente, os atores sociais envolvidos. Deste modo, da mesma forma que no acesso à informação ambiental, verifica-se, como já citado supra, que o acesso à participação nos processos decisórios dos instrumentos da política ambiental não é nem prévio, nem efetivo.

Quanto ao acesso à justiça, segundo a ABDL, no Brasil há um bom amparo legal em relação à defesa judicial e ao dano ambiental, mas no caso da participação deixa a desejar, visto que é um campo totalmente dependente de interpretações e adaptações de instrumentos legais diferenciados. Salienta, assim, a inexistência de um instrumento legal específico para a defesa do cidadão que se sentir lesado em seu direito de participação (ABDL, 2005).

Sendo assim, face aos nefastos resultados apresentados no concernente à participação da sociedade civil em processo decisório de instrumentos da PNMA no Brasil, há que se qualificá-la negativamente em razão, prioritariamente: dela não estar sendo incentivada; por haver ausência de meios legais para lhe dar suporte; por haver carência de informação; pelo fato da população ser apenas ouvida, não sendo dado crédito, por conseguinte, aos seus interesses; em razão de ao ser realizada - pois há casos em que ela é excluída, em sua maioria -, isso acontecer apenas no meio do processo decisório; e, em tempo, há que se ressaltar, tendo por parâmetro a escada de participação de Arnstein (1969) - que classifica a participação entre os graus 1 e 8 -, que o nível de participação no Brasil se enquadra, de forma geral, 
nos níveis mais baixos, ou seja, situa-se entre os graus $\underline{1 \mathrm{e}}$ $\underline{3}$, sendo capaz, em algumas raras situações, de chegar a 5 .

Verifica-se, portanto, que este importante princípio constitucional está sendo subaplicado no Brasil. Estes, frisem-se, são alguns dos meandros presentes no momento transicional atual que, aliados a muitos outros, têm contribuído para que a participação da sociedade civil ainda não se tenha concretizado efetivamente no país, a despeito da relevância do tema.

\section{Conclusão}

Como descrito no transcorrer deste texto, o sistema de desenvolvimento adotado pela sociedade hodierna encontra-se, ainda hoje, fundamentado em uma lógica política, econômica e cultural que privilegia o acúmulo de riquezas econômicas sem considerar, adequadamente, os fatores sociais e ambientais. Este proceder tem influído e levado os seres humanos a consumir muito além da capacidade de suporte da biosfera. Isto, via de regra, tem provocado a sobrecarga de poluentes no meio ambiente implicando, não infrequentemente, em depleção irreversível das reservas naturais, gerando, desta forma, impactos ambientais de elevada monta.

Este é um dos motivos, se não o fundamental, de se aprimorarem os instrumentos, as técnicas e os processos comunicativos de forma a incentivar a ampla e irrestrita participação da sociedade civil em processos de tomada de decisão ambiental, uma vez que sem a mesma, tais procedimentos estarão atendendo, tão somente, aos interesses do capital e do desenvolvimento de grupos que o detêm. Além disso, em razão de tais processos decisórios encontrarem-se centrados nas mãos do Poder Executivo, em todos os seus níveis, podem acabar gerando imobilidade, impotência e um campo fértil para o tráfico de influências.

Frise-se, ademais, que já se passaram vinte e três anos da promulgação da Constituição Federal e trinta da
Lei da Política Ambiental Nacional e, até o momento, tal forma de manifestação cidadã, prevista na legislação, é continuamente obstaculizada, sonegada, mantendo, ainda, um caráter de cunho eminentemente retórico na práxis do poder público.

Este, portanto, é o grande desafio que se apresenta à civilização atual. Vale dizer que romper tais barreiras em prol desta nova ideologia é a pedra basilar deste novo milênio. Neste sentido, a alternativa da participação deve ser vista pela ótica dos níveis de concessão dos espaços de poder. Isto se deve ao fato de que os processos participativos quando assim aplicados, embora possam apresentar algumas dificuldades na sua efetiva implementação, contribuem para uma melhor análise dos problemas, uma maior legitimidade e representatividade, bem como sua consequente lógica, que se traduz na intensificação da responsabilidade da sociedade civil perante o meio ao qual pertence.

A defesa da participação, nesta perspectiva, não diz respeito apenas a um princípio democrático, mas, essencialmente, a uma parte indispensável na construção de um novo processo de gestão dos recursos públicos. A participação, assim entendida, vai além de um complemento protetor para os arranjos institucionais, isto porque ela proporciona um efeito psicológico positivo sobre aqueles que fazem parte de um processo decisório coletivo, garantindo, por conseguinte, um fluxo interacional ininterrupto entre o funcionamento das instituições e as qualidades e atitudes psicológicas dos indivíduos que se encontram dentro delas.

Vale relembrar que tal forma de intervenção social permitirá aos partícipes se perceberem e atuarem como representantes da coletividade que, ao compartilharem uma determinada situação, têm a oportunidade de se sentirem como sujeitos integrantes de um mesmo processo, com interesses, expectativas e demandas comuns, detendo, igualmente, a autonomia necessária para transformá-los em ação coletiva, frente a outros atores sociais e políticos. 


\section{Referências}

ALONSO, Ângela; COSTA, Valeriano. Dinâmica da participação em questões ambientais: uma análise das audiências públicas para o licenciamento ambiental do Rodoanel. In: COELHO, Vera; Schattan, P.; NOBRE, Marcos. (Org.). Participação e deliberação: teorias democráticas e experiências institucionais no Brasil contemporâneo. São Paulo: Ed. 34, 2004. p. 290-312.

ARNSTEIN, Sherry R. A ladder of citizen participation. Journal of the American Institute of Planners, Cambridge, v. 35, n. 4, p. 216-224, July 1969.

ASSOCIAÇÃO BRASILEIRA PARA O DESENVOLVIMENTO DE LIDERANÇAS, INSTITUTO SOCIOAMBIENTAL. Projeto Iniciativa de Acesso no Brasil. São Paulo: ABDL/ ISA, 2005.

BARROS, Lucivaldo Vasconcelos. A nova Lei do Direito à Informação Ambiental. Revista Sociedade Paranaense de Ensino e Informática, Curitiba: SPEI, v. 5, n. 1. p. 7-13, 2004.

BATISTELA, Tatiana S. O zoneamento ambiental e o desafio da construção da gestão ambiental urbana. Dissertação (Mestrado) - UnB. Brasília, 2007.

BORDENAVE, Juan E. Díaz. O que é participação. 8. ed. São Paulo: Brasiliense, 1994.

BRASIL. Diretrizes Básicas do Zoneamento Industrial. Lei 6.803, de 02 de julho de 1980. Brasília, 1980.

. Política Nacional do Meio Ambiente. Lei 6.938, de 31 de agosto de 1981. Brasília, 1981.

Relatório de Impacto Ambiental. Resolução 001, de 23 de janeiro de 1986. Brasília: Conselho Nacional do Meio Ambiente, 1986.

Constituição da República Federativa do Brasil. Brasília: Congresso Nacional, 1988.

. Ministério do Meio Ambiente dos Recursos Hídricos e da Amazônia Legal. Instituto Brasileiro do Meio Ambiente e dos Recursos Naturais renováveis. Avaliação de impacto ambiental: agentes sociais, procedimentos e ferramentas. Brasília: IBAMA, 1995.

Zoneamento Ecológico Econômico. Decreto 4.297, de 10 de julho de 2002. Brasília, 2002.

CORAZZA, Rosana Icassati. Do debate científico à política pública: polarização das discussões acadêmicas entre biólogos nos anos 70 e instrumentalização econômica das políticas ambientais. Revista de Ciência e Tecnologia, Piracicaba, v. 8, n. 16, p. 107-118, dez. 2000.

DOELLE, Meinhard; SINCLAIR, A. John. Time for a new approach to public participation in EA: promoting cooperation and consensus for sustainability. Environmental Impact Assessment Review, New York, v. 26, n. 2, p.185-205, Mar. 2006.

FINK, Daniel Roberto et al. Aspectos jurídicos do licenciamento ambiental. Rio de Janeiro: Forense. 2004.

FLORIANO, Eduardo Pagel. Politicas de gestão ambiental. Santa Rosa: ANORGS, 2004. (Caderno Didático, 7).

FURRIELA, Rachel Biderman. A lei brasileira sobre acesso à informação ambiental como ferramenta para a gestão democrática do meio ambiente. Disponível em: <http://www.lead. org/filemanager/do wnload/422/Artigo_Lei_Info_Ambiental. pdf>. Acesso em: 20/08/2006.

JAMES, Rosemary F.; BLAMEY, Russel K. Public participation in environmental decision-making - rhetoric to reality? In: INTERNATIONAL SYMPOSIUM ON SOCIETY AND RESOURCE MANAGEMENT, 1999, Brisbane. Proceedings... Austrália, 1999. p. 1-25.

LANNA, Antonio Eduardo. A gestão dos recursos hídricos no contexto das políticas ambientais: a inserção da gestão das águas na gestão ambiental. Disponível em: $<$ http://www.uff. $\mathrm{br} /$ cienciaambiental/biblioteca/rhidricos/parte2.pdf $>$. Acesso em: 25/07/2007.

MACHADO, Paulo Leme Affonso. Direito Ambiental Brasileiro. 9. ed. São Paulo: Malheiros, 2001.

MOREIRA, Iara Dias Verocai. Avaliação de impactos no Brasil: antecedentes, situação atual e perspectivas futuras. In: Manual de Avaliação de Impactos Ambientais. 2. ed. Curitiba: SUREHMA/GTZ, 1995. $0331-1-4$.

OLIVEIRA, Isabel S. D. de. A contribuição do zoneamento ecológico econômico na avaliação de impacto ambiental: bases e propostas metodológicas. Dissertação (Mestrado) - USP. São Carlos, 2004.

QUEIROZ, Sandra Mara Pereira de. (1995). Objetivos e componentes dos procedimentos para a avaliação de impacto ambiental. In: Manual de Avaliação de Impactos Ambientais. 2. ed. Curitiba: SUREHMA/GTZ, 1995.

SÁNCHEZ, Luis Enrique. Avaliação de impacto ambiental: conceitos e métodos. São Paulo: Oficina de Textos, 2006. 
SÃO PAULO (Estado). Companhia de Tecnologia de Saneamento Ambiental. Licenciamento ambiental. São Paulo: Secretaria do Estado do Meio Ambiente, 2007.

SILVA, Gustavo Tavares da. Participação cidadã nas políticas públicas. In: . Participação cidadã: novos conceitos e metodologias. Fortaleza: Expressão, 2004. p. 61-85.

SOUZA, Marcelo Pereira de. Instrumentos de gestão ambiental: fundamentos e prática. São Carlos: Riani Costa, 2000.

et al. A necessidade de incorporação do zoneamento ambiental como instrumento de planejamento e gestão territorial urbana. In: INTERNATIONAL CONGRESS ON ENVIRONMENTAL PLANNING AND MANAGEMENT, 2005, Brasília. Proceedings... Brasília: Universidade Católica de Brasília, 2005. p. 1-22.

UNITED NATIONS ECONOMIC COMMISSIONS FOR EUROPE. Guidance on public participation. In: CONVEN-
TION ON ENVIRONMENTAL IMPACT ASSESSMENT (EIA) IN A TRANSBOUNDARY CONTEXT, 2004, Cavtat. Proceedings... Geneva: UNECE, 2004. p. 1-16.

VALLE, Raul Silva Telles. Direito à informação: marco legal. São Paulo: ABDL/ISA, 2005.

VEGA, Raúl Pacheco; LÓPEZ, Obdulia. Dos Modalidades de participación ciudadana en política ambiental. Revista Sociedad y Territorio, Chile, v. 3, n. 9, p. 25-62, 2001.

ZHAVORONKOVA, Natália G. et al. Public participation in the process of environmental decision-making: designing, implementing and enforcing environmental standards. Russia: Saladin \& Pikul, 1997.

ZHOURI, André; LASCHEFSKI, Klemens; PEREIRA, Doralice Barros. (Org.). A insustentável leveza da política ambiental: desenvolvimento e conflitos socioambientais. Belo Horizonte: Autêntica, 2005.

Recebido em janeiro de 2012. Aceito em maio de 2012. Publicado em junho de 2012. 